\title{
The relationship between sleep condition and autonomic nervous function in women in their 70s with type 2 diabetes mellitus
}

\author{
Miki Sato ${ }^{1 \#}$, Yuko Yasuhara ${ }^{2}$, Tetsuya Tanioka ${ }^{2}$, Yukie Iwasa $^{2}$, Masafumi Miyake $^{3}$, \\ Haruo Kobayashi ${ }^{4}$, Rozzano C. Locsin ${ }^{5}$, Seizo Kinoshita ${ }^{6}$, Masatoshi Masuda ${ }^{6}$, \\ Hiroshi Shimizu ${ }^{7}$ \\ ${ }^{1}$ Department of Nursing, Faculty of Nursing, Shikoku University, Tokushima, Japan; \\ ${ }^{\#}$ Corresponding Author: msato@,shikoku-u.ac.jp \\ ${ }^{2}$ Department of Nursing, Institute of Health Biosciences, The University of Tokushima Graduate School, Tokushima, Japan \\ ${ }^{3}$ Tokushima Prefectural Minami Health Care Center, Tokushima, Japan \\ ${ }^{4}$ Faculty of Medical Welfare, Kawasaki University of Medical Welfare, Kurashiki, Japan \\ ${ }^{5}$ Christine E. Lynn College of Nursing, Florida Atlantic University, Boca Raton, USA \\ ${ }^{6}$ Kinoshita Hospital, Tokushima, Japan \\ ${ }^{7}$ Toyo Hospital, Tokushima, Japan
}

Received 30 August 2013; revised 8 October 2013; accepted 14 October 2013

Copyright (C) 2013 Miki Sato et al. This is an open access article distributed under the Creative Commons Attribution License, which permits unrestricted use, distribution, and reproduction in any medium, provided the original work is properly cited.

\section{ABSTRACT}

The aim of this study was to determine the relationship between sleep condition and autonomic nervous function of women in their 70 s with type 2 diabetes mellitus by analyzing the activity counts (AC) on actigraphs and heart rate variability (HRV). Ten healthy women in their 30 s to 40 s as control and four women patients with type 2 diabetes in their 70 s wore the electrocardiograph and an actigraph for $\mathbf{2 4}$ hours while keeping a diary of activities, including their sleep and food intake. The Pittsburgh Sleep Quality Index was used to assess subjective sleep conditions. The subjective sleeping results were significantly correlated with those measured by the AC and HRV. However, AC and HRV correlation pattern showed different activity in the patients with type 2 diabetes mellitus. The quality of sleep of those with chronic diabetes was not good even if their HbA1c was well controlled. Furthermore, their automatic nervous function was different from the control group. The sleeping hours of patients with type 2 diabetes were shorter or longer than those of healthy women. Ultimately, this study maintains that it is important to examine automatic nervous functions using objective examination index during the

*Conflict of interest statement: None of the authors have any conflicts of interest to declare. early stage of diabetes mellitus.

Keywords: Actigraphy; Heart Rate Variability; Autonomic Nervous Function; Sleep Condition; Diabetes; HbAlc

\section{INTRODUCTION}

Recent epidemiological, biological, and behavioral evidence suggests that sleep disorders may contribute to the development of diabetes; conversely, diabetes itself may contribute to sleep disorders [1]. The mortality rates of individuals with diabetes, high-blood pressure, or a sleep disturbance are high [2,3], and sleep disturbances notably increase blood glucose levels and blood pressure [4,5]. Furthermore, a lack of sleep causes a decrease in glucose tolerance and an increase in appetite [6]. The highest risk of diabetes has been found in individuals with insomnia and $\leq 5$ hours sleep duration group (odds ratio $[95 \% \mathrm{CI}]$ $2.95[1.2-7.0])$. Insomnia with short sleep duration is associated with increased odds of diabetes. Objective sleep duration may predict the cardio metabolic morbidity of chronic insomnia [7]. Sleep apnea increases the risk of developing diabetes, independent of other risk factors. Among patients with more severe sleep apnea, regular positive airway pressure use may attenuate this risk [8].

Nocturia can result from poorly controlled diabetes [9]. Nocturia is also one of the most bothersome of all 
urologic symptoms, yet even a rudimentary classification does not exist [10]. Multiple factors may cause nocturia, such as behavioral or environmental factors and pathologic conditions, including cardiovascular disease, diabetes mellitus, lower urinary tract obstruction, anxiety or primary sleep disorders, and sleep apnea [11,12]. It is important for healthcare providers to address the quality and duration of sleep in patients with type 2 diabetes.

In people who already have diabetes, sleep deprivation contributes to elevations of HbA1c [13-17]. Lamond et al. [18] found that, within a diabetic sample, the severity of diabetes was related to sleep disruption. Their path analysis findings indicated that the relationship between type 2 diabetes and sleep disruption was mediated by physical complications of the disease (pain and nocturia), and not by either obesity or emotional adjustment. Chasens et al. [19] also reported that diabetic women, persons with lower urinary tract symptoms, and those reporting excessive daytime sleepiness had a significant three to six-fold increased risk for nocturia (greater than or equal to two episodes per night).

The aim of this study was to determine whether there is a relationship between sleeping and conditions related to sleep patterns and related situations and autonomic nervous function in women in their 70s who have type 2 diabetes mellitus.

\section{METHODS}

\subsection{Study Design}

Heart rate variability (HRV) can be non-invasively determined and used to investigate autonomic nervous functioning, especially the balance between parasympathetic and sympathetic nervous system activities [20]. The low frequency (LF) component $(0.04-0.15 \mathrm{~Hz})$ is extracted by power spectrum density. The high frequency $(\mathrm{HF})$ component $(0.15-0.50 \mathrm{~Hz})$ is extracted and serves as an indicator of parasympathetic nervous system activity. The $\mathrm{LF} / \mathrm{HF}$ ratio indicates sympathetic nervous system activity.

Actigraphy is used to assess the balance between hours of waking-activity and sleep and the conditions of a sleep disturbance [21]. Activity counts (AC) on an actigraph indicate the amount of activity exceeding 0.01 $\mathrm{G} / \mathrm{min}$ during an epoch of 1 minute. The $\mathrm{G}$ represents gravitational acceleration $\left(9.8 \mathrm{~m} / \mathrm{sec}^{2}\right)$. Participants with actigraphs were divided into "up" (daytime activity) intervals, defined as the period of time participants reported being out of bed, and "down" (sleep) intervals, defined as the period during which participants were in bed.

\subsection{Measurement Methods}

1) Actigraph: a micro mini-type actigraph (Ambula- tory Monitoring, Inc., Ardsley, NY, USA) was attached on the patient's non-dominant arm for 3 days starting from 18:00 on day 1.

2) ECG recordings. Electrodes were placed on the chest, and ECG recordings were made by Holter electrocardiogram: Participants also wore a Holter electrocardiograph for 24 hours.

3) Diary: Participants kept a daily log of the time they awoke in the morning and went to bed and descriptions of meals, work, and exercise for 3 days.

4) PSQI: Pittsburgh Sleep Quality Index, participants completed the Japanese version of the PSQI on the final day of the study. The PSQI is an internationally standardized scale, and the Japanese version (Cronbach $\alpha=$ 0.77 ) is reliable and appropriate for assessing lack of sleep and its subjective quality [22]. The cut-off is regarded as 6 points [23,24].

5) The condition of sleep when the participants wore both the actigraph and the HRV analyzer was assessed at a post-measurement interview with each participant.

6) Sleep hours were obtained from the actigraph records.

\subsection{Data Analysis and Data Collection Period}

1) First, a group of healthy young women underwent actigraphy and autonomic nervous system evaluation by HRV, in order to compare their results with those of elderly women with diabetes mellitus. The control group consisted of healthy, women in their 20 s to 40 s who did not have menopausal symptoms nor hormonal changes. They did not have any cardiac disease, psychiatric disorders, diabetes mellitus, or subjective sleep disturbances. They could independently maintain a daily log of activties. Their mean PSQI was $3.1 \pm 1.85$ points. Women in this age group with well-balanced autonomic nervous activities were found to be generally healthy, thereby meeting the criteria to comprise the control group.

2) Patients with type 2 diabetes. There were four patients. Each patient's case is described below:

Case A: A woman in her 70s. HbA1c (National Glycohemoglobin Standardization Program: NGSP) $=5.9 \%$, $\mathrm{PSQI}=3$ points. $\mathrm{BMI}=25.9 \mathrm{~kg} / \mathrm{m}^{2}$. HbAlc (NGSP) had tended to be high at $6.4 \%$, but it was well controlled by following the exercise and diet plan given while visiting the hospital.

Case B: A woman in her 70s. HbAlc $($ NGSP) $=6.6 \%$, PSQI $=15$ points. BMI $=22.0 \mathrm{~kg} / \mathrm{m}^{2}$. She was diagnosed with gestational diabetes at the birth of her third child, and since then, she has been in treatment for nearly 30 years. She had accidentally overdosed on insulin and been hospitalized with low blood sugar. Her control of diabetes was poor.

Case C: A woman in her 60 s being treated with insulin 
for diabetes. HbA1c (NGSP) $=9.0 \%$, PSQI $=9$ points, $\mathrm{BMI}=27.1 \mathrm{~kg} / \mathrm{m}^{2}$. It was the 10 th year since she was diagnosed with diabetes and started to be treated with insulin. However, disease control was poor, and the dose of insulin was increasing.

Case D: A woman in her 70s being treated with insulin for diabetes. HbA1c (NGSP) $=10.4 \%$, PSQI $=6$ points, $\mathrm{BMI}=23.6 \mathrm{~kg} / \mathrm{m}^{2}$. It was the 15 th year since she was diagnosed with diabetes. She was being treated with insulin.

3) Data collection period: Data were collected from June 2012 to January 2013.

\subsection{Analytical Method}

The data obtained from the actigraphs were analyzed using AW2 software (Ambulatory Monitoring, Inc.). Time series data of RR intervals were formalized from the FM180 electrocardiograph (Fukuda Denshi Co. Ltd., Tokyo, Japan) using Holter software (Fukuda Denshi Co. Ltd.), and the HRV was analyzed using Mem Calc/ CHIRAM (GMS Co., Tokyo, Japan).

The AC counts were matched with the HRV data produced over 5-minute intervals. Correlations between AC and parasympathetic and sympathetic nervous system activities were analyzed using Pearson's product-moment correlation coefficient. Differences between average values of parasympathetic nervous system activity during the daytime and while asleep, and between average values of sympathetic nervous system activity in the daytime and while asleep were assessed using an unpaired $t$-test. Statistical analysis was carried out using PASW Statistics version software 18; statistical significance was set at $p<0.05$.

\subsection{Ethical Considerations}

The data were managed according to the Private Information Protection Law, with approval by the Tokushima University Hospital Ethics Board (Approval number 1558) and the cooperation of the hospital staff. A member of the interdisciplinary team obtained written, informed consent from healthy women in their $20 \mathrm{~s}$ to $40 \mathrm{~s}$ who comprised the control group and from the patients and their families after they received an explanation of the study. They were assured that their personal information would be protected, reported as aggregate, and used only for research purposes.

\section{RESULTS}

\subsection{Actigraph Values and Heart Rate Variability}

Table 1 shows the actigraph data and heart rate variabilities of all subjects. Among the healthy individuals, the $\mathrm{AC}$ data were significant but negatively correlated

Table 1. A comparison of actigraph values and heart rate variability in healthy women subjects and women patients with type 2 diabetes.

\begin{tabular}{|c|c|c|c|c|c|c|c|c|c|c|}
\hline & $\begin{array}{c}\text { Correlation } \\
\# 2\end{array}$ & $\mathrm{r}$ & $p$ & $\begin{array}{l}\text { Autonomic } \\
\text { nervous } \\
\text { activity \#3 }\end{array}$ & $\begin{array}{l}\text { Up interval (day time } \\
\text { activity) (mean } \pm \text { SD) }\end{array}$ & $\begin{array}{c}\text { Down interval } \\
\text { (sleep) }(\text { mean } \pm \mathrm{SD})\end{array}$ & $\mathrm{t}$ & $p$ & $\begin{array}{l}\text { Sleep } \\
\text { duration } \\
\text { (min.) }\end{array}$ & $\begin{array}{c}\text { Sleep } \\
\text { efficiency (\%) }\end{array}$ \\
\hline $\begin{array}{l}\text { Healthy } \\
\text { Individuals } \\
(\mathrm{n}=10)\end{array}$ & AC vs. $\mathrm{HF}^{\S}$ & $-0.43--0.73$ & $<0.001$ & $\mathrm{HF}\left(\mathrm{msec}^{2}\right)$ & $\begin{array}{c}77.33 \pm 40.76- \\
552.64 \pm 367.24\end{array}$ & $\begin{array}{c}3.04 \pm 2.75- \\
6.73 \pm 4.03\end{array}$ & $\begin{array}{c}4.45 \text { to } \\
19.03\end{array}$ & $<0.001$ & \multirow[t]{2}{*}{$449 \pm 112$} & \multirow[t]{2}{*}{$86.38-98.76$} \\
\hline$\# 1$ & $\begin{array}{l}\mathrm{AC} \text { vs. } \\
\mathrm{LF} / \mathrm{HF}^{\S}\end{array}$ & $0.45-0.62$ & $<0.001$ & $\begin{array}{c}\mathrm{LF} / \mathrm{HF} \\
\text { ratio }\end{array}$ & $\begin{array}{c}230.98 \pm 77.80- \\
2240.90 \pm 921.85\end{array}$ & $\begin{array}{c}0.92 \pm 1.23- \\
4.04 \pm 1.87\end{array}$ & $\begin{array}{c}8.16 \text { to } \\
18.9\end{array}$ & $<0.001$ & & \\
\hline \multicolumn{11}{|l|}{$\begin{array}{c}\text { Patients with } \\
\text { Diabetes }(n=4)\end{array}$} \\
\hline \multirow{2}{*}{ HbAlc $5.9 \%$} & & -0.478 & $<0.001$ & & $155.65 \pm 197.72$ & $578.43 \pm 380.20$ & 8.86 & $<0.001$ & \multirow{2}{*}{336} & \multirow{2}{*}{96.05} \\
\hline & & 0.378 & $<0.001$ & & $3.06 \pm 2.49$ & $0.62 \pm 0.720$ & 12.85 & $<0.001$ & & \\
\hline \multirow{2}{*}{ HbAlc $6.6 \%$} & & 0.129 & NS & & $54.64 \pm 40.23$ & $45.18 \pm 23.37$ & 2.50 & $<0.001$ & \multirow{2}{*}{606} & \multirow{2}{*}{86.84} \\
\hline & & -0.158 & NS & & $1.58 \pm 1.59$ & $2.63 \pm 1.59$ & 0.86 & NS & & \\
\hline \multirow{2}{*}{ HbAlc $9.0 \%$} & & -0.275 & $<0.001$ & & $66.58 \pm 60.31$ & $94.40 \pm 72.35$ & 2.76 & $<0.001$ & \multirow{2}{*}{308} & \multirow{2}{*}{87.04} \\
\hline & & 0.338 & $<0.001$ & & $3.62 \pm 2.29$ & $2.71 \pm 2.77$ & 2.36 & $<0.050$ & & \\
\hline \multirow{2}{*}{ HbAlc $10.4 \%$} & & -0.391 & $<0.001$ & & $38.63 \pm 38.01$ & $74.47 \pm 56.28$ & 6.05 & $<0.001$ & \multirow{2}{*}{600} & \multirow{2}{*}{93.93} \\
\hline & & -0.106 & NS & & $8.29 \pm 9.32$ & $7.10 \pm 6.49$ & 1.27 & NS & & \\
\hline
\end{tabular}

HF: high frequency; LF/HF: ratio of high-frequency to low-frequency components; ${ }^{\S}$ The value for 24 hours from 6 p.m. on one day to 6 p.m. the next day, and the range of values of healthy individuals (Minimum-Maximum); r: Pearson's product-moment correlation coefficient. Up intervals = daytime activity, "Down intervals" = sleep. HbAlc (NGSP) \% \#1: range of analysis results; \#2: upper row: correlation between AC (activity count) and HF; lower row: correlation between $\mathrm{AC}$ and LF/HF; \#3: upper row: mean of $\mathrm{HF}\left(\mathrm{msec}^{2}\right) \pm \mathrm{SD}$; lower row: mean of LF/HFratio $\pm \mathrm{SD}$, NS: not significant. 
with HF (range of $r=-0.43$ to $-0.73, p<0.001$ ) and positively correlated with the LF/HF ratio (range of $r=$ 0.45 to $0.62, p<0.001$ ).

On the other hand, the results of patients with type 2 diabetes are described below.

In Case $\mathrm{A}$, the $\mathrm{AC}$ data correlated significantly negatively with HF $(r=-0.487, p<0.001)$ and positively with the LF/HF ratio $(r=0.378, p<0.001)$.

In Case $\mathrm{B}$, the $\mathrm{AC}$ data were not correlated with the HF $(r=0.129, \mathrm{NS})$, but were positively correlated with the $\mathrm{LF} / \mathrm{HF}$ ratio $(r=-0.158, N S)$.

In Case $\mathrm{C}, \mathrm{AC}$ data showed a weak but significant negative correlation with $\mathrm{HF}(r=-0.275, p<0.001)$ and a positive correlation with the LF/HF ratio $(r=0.33, p<$ $0.001)$.

In Case D, AC data showed a weak but significant negative correlation with HF $(r=-0.391, p<0.001)$, but AC data were not significantly correlated with the LF/HF ratio $(r=-0.106, N S)$.

The HF during daytime activities and while asleep differed significantly (77.33 \pm 40.76 to $552.64 \pm 367.24$ $\mathrm{msec}^{2}$ vs. $230.98 \pm 77.80$ to $2240.90 \pm 921.85 \mathrm{msec}^{2} ; t=$ 4.45 to $19.03, p<0.001$ ) in the healthy individuals, as did the LF/HF ratio during daytime activities and during sleep $(3.04 \pm 2.75$ to $6.73 \pm 4.03$ vs. $0.92 \pm 1.23$ to $4.04 \pm$ $1.87, t=8.16$ to $18.9, p<0.001$ ).

Among patients with diabetes mellitus, the following were found.

In Case A, the HF during daytime activities and while asleep was significantly different $(155.65 \pm 197.72$ vs. $578.43 \pm 380.20, t=8.86, p<0.001$ ), and the LF/HF ratio during daytime and during sleep also differed significantly $(3.06 \pm 2.49$ vs. $0.62 \pm 0.720, t=12.85, p<$ $0.001)$.

In Case B, the HF during daytime activities and while asleep differed significantly (54.64 \pm 40.23 vs $45.18 \pm$ $23.37 \mathrm{msec}^{2}, t=2.50, p<0.001$ ), and the LF/HF ratio during daytime and during sleep also differed significantly $(1.58 \pm 1.59$ vs. $2.63 \pm 1.59, t=0.86, N S)$.

In Case $\mathrm{C}$, the HF during daytime activities and while asleep differed significantly $(66.58 \pm 60.31$ vs. $94.40 \pm$ $72.35 \mathrm{msec}^{2}, t=2.76, p<0.001$ ), and the LF/HF ratio during daytime and during sleep also differed significantly $(3.62 \pm 2.29$ vs. $2.71 \pm 2.77, t=2.36, p<0.05)$.

In Case D, the HF during daytime activities and while asleep differed significantly $(38.63 \pm 38.01$ vs. $74.47 \pm$ $56.28 \mathrm{msec}^{2}, \mathrm{t}=6.05 \mathrm{p}<0.001$ ), and the LF/HF ratio during daytime and during sleep also differed significantly $(8.29 \pm 9.32$ vs $7.10 \pm 6.49, t=1.27, N S)$.

The sleep time of healthy women was $449 \pm 119$ minutes, while among the subjects with type 2 diabetes, the sleep time was 336 minutes for Case A, 606 minutes for Case B, 308 minutes for Case C, and 600 minutes for Case D.
The sleep efficiency was $86.38 \%-98.78 \%$ in healthy women, while in the subjects with type 2 diabetes, the sleep efficiency $96.05 \%$ in Case A, $86.84 \%$ in Case B, $87.04 \%$ in Case C, and $93.93 \%$ in Case D.

\subsection{Parasympathetic and Sympathetic Activity during Sleep}

Figure 1(a) shows that the average HF values of healthy participants during sleep were distributed from 230.98 to $1219.24 \mathrm{msec}^{2}$. Figure 1(b) shows that the average $\mathrm{HF}$ values of patients with type 2 diabetes were distributed from 74.47 to $578.43 \mathrm{msec}^{2}$. Figure 1(c) shows that the average LF/HF ratios during sleep among the healthy women ranged from 1.13 to 4.46, and Figure 1(d) shows that the average LF/HF ratios were distributed from 1.30 to 7.10 in patients with type 2 diabetes.

Figure 2 shows a typical example of the distribution of hours that a healthy participant spent in a sleeping state.

Subjective sleep hours (reported in the daily $\log$ ) agreed with the actigraphic findings of 5 hours and 39 $\min (339 \mathrm{~min}$ ). The sleep efficiency was $97.06 \%$. Parasympathetic nervous system activity started to increase about 2 hours before bedtime (22:00), and started to decline about 1 hour before awakening (06:00). Sympathetic nervous system activity gradually increased about 3 hours before waking (04:00), with some increases or decreases occurring during the daytime, and the activity started to decline in the early evening. The AC correlated significantly negatively with $\mathrm{HF}(r=-0.603, p<0.01)$ and with $\mathrm{LF} / \mathrm{HF}(r=0.568, p<0.01)$.

The HF components during daytime activities and while asleep differed significantly $(45.45 \pm 25.38$ vs. $\left.246.07 \pm 124.95 \mathrm{msec}^{2} ; t=12.99, p<0.001\right)$. The LF/HF during daytime activities and during sleep also differed significantly $(11.37 \pm 5.97$ vs. $3.49 \pm 5.30$ ratio; $t=8.92$, $p<0.001)$.

Figure 3 shows a typical example of a woman patient in her 70s with type 2 diabetes who injects insulin four times daily. The PSQI score was 6 points, and she had no subjective sleep disturbance. The actigraph recorded 10 hours $(600 \mathrm{~min})$ of sleep, and the sleep efficiency was 93.93\%. Moreover, she spent up to 10 hours sleeping and remaining in bed for over half the day, every day. The duration of subjective sleep and that recorded by the actigraph differed by about $30 \mathrm{~min}$.

Although she claimed to have slept well, parasympathetic nervous activity did not indicate activity during the night and actually seemed similar between the daytime data and while asleep at night. The AC and HF showed significant correlations $(r=-0.391, p<0.001)$, but LF/ HF $(r=-0.106, N S)$ did not show any significant correlation. Actigraphic recordings showed that she awakened to use the toilet twice, at 2:30 $\mathrm{AM}$ and at 6:50 $\mathrm{AM}$. The 
$\mathrm{msec}^{2}$

HF (msec $\left.{ }^{2}\right)$

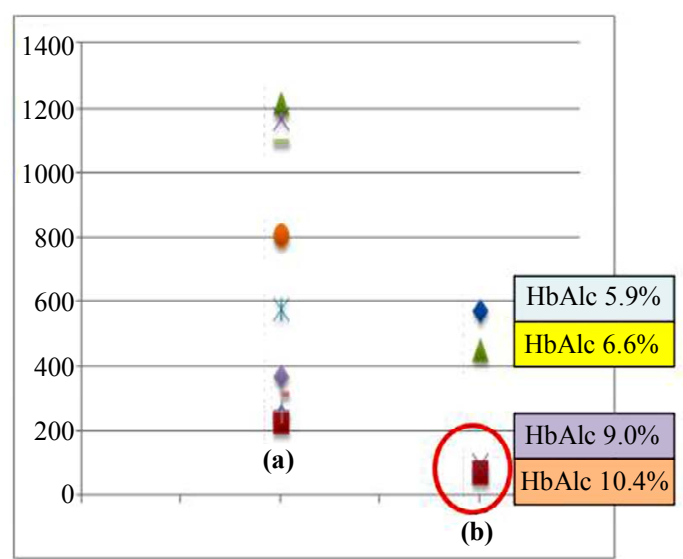

Healthy women $\mathrm{n}=10$
Patients with diabetes $\mathrm{n}=4$
LF/HF (ratio)

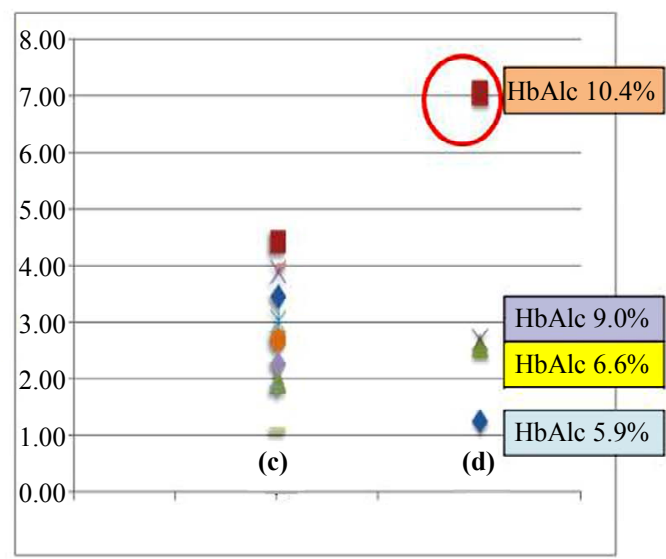

Patients with

diabetes $n=4$

HbAlc (NGSP) \%

Figure 1. Average parasympathetic and sympathetic activities during sleep periods in healthy women subjects compared to patients with type 2 diabetes. (a) Average HF values among the healthy women; (b) Average HF values of patients' with type 2 diabetes; (c) Average LF/HF ratio among the healthy women; (d) Average LF/ HF ratio among patients' with type 2 diabetes. HF, high frequency; LF/HF, ratio of high-frequency to low-frequency components.

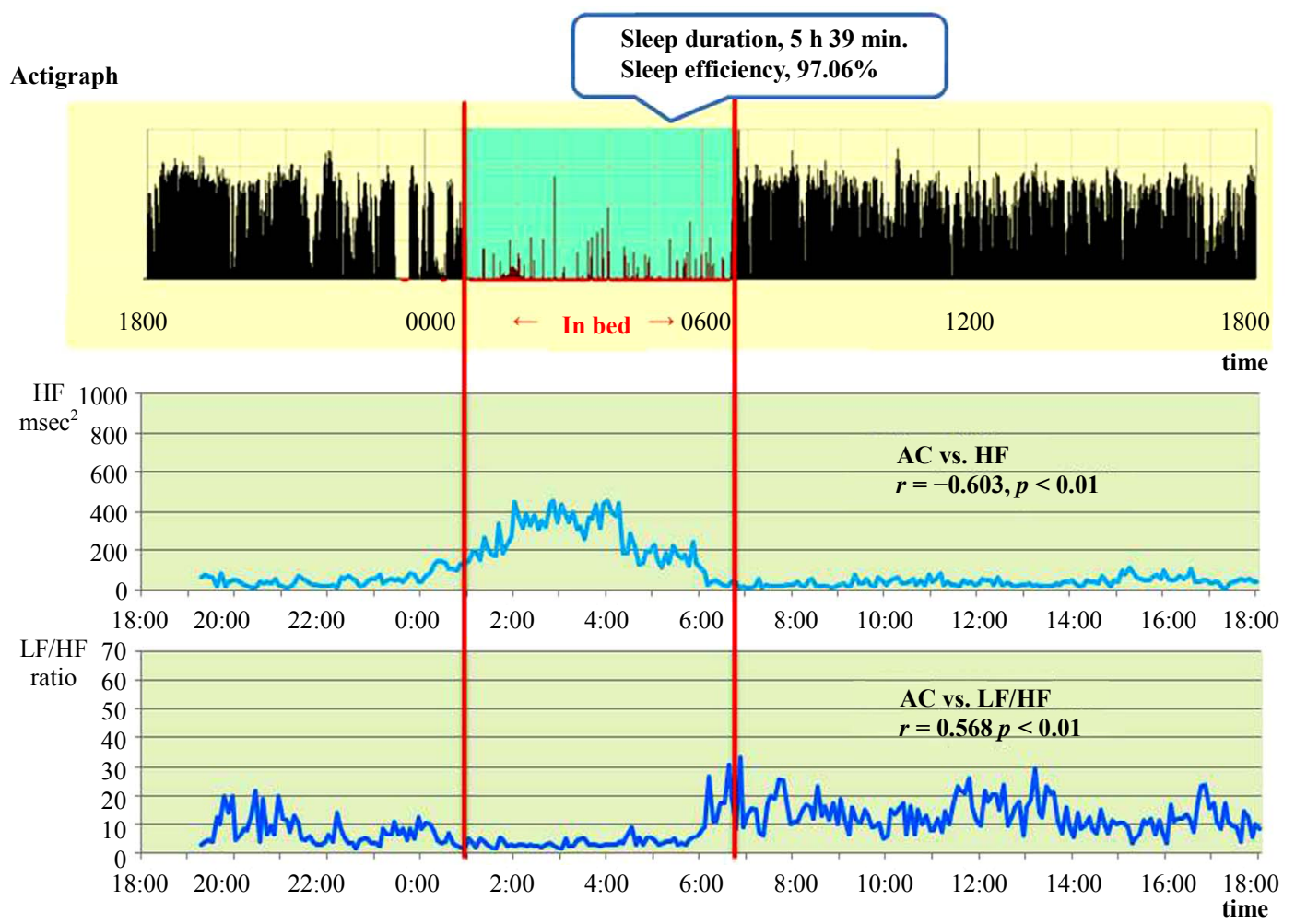

$\mathrm{HF}$, high frequency; LF/HF, ratio of high-frequency to low-frequency components; AC, activity count. Red line, sleep duration.

Figure 2. Typical example of a healthy woman: association between activity counts and parasympathetic and sympathetic nervous activity.

HF during active hours and while asleep differed significantly $\left(38.63 \pm 38.01\right.$ vs. $74.47 \pm 56.28 \mathrm{msec}^{2} ; t=$
$6.05, p<0.001)$, whereas the $\mathrm{LF} / \mathrm{HF}$ ratio did not $(8.29 \pm$ 9.32 vs. $7.10 \pm 6.49 ; t=1.27, N S$ ). 


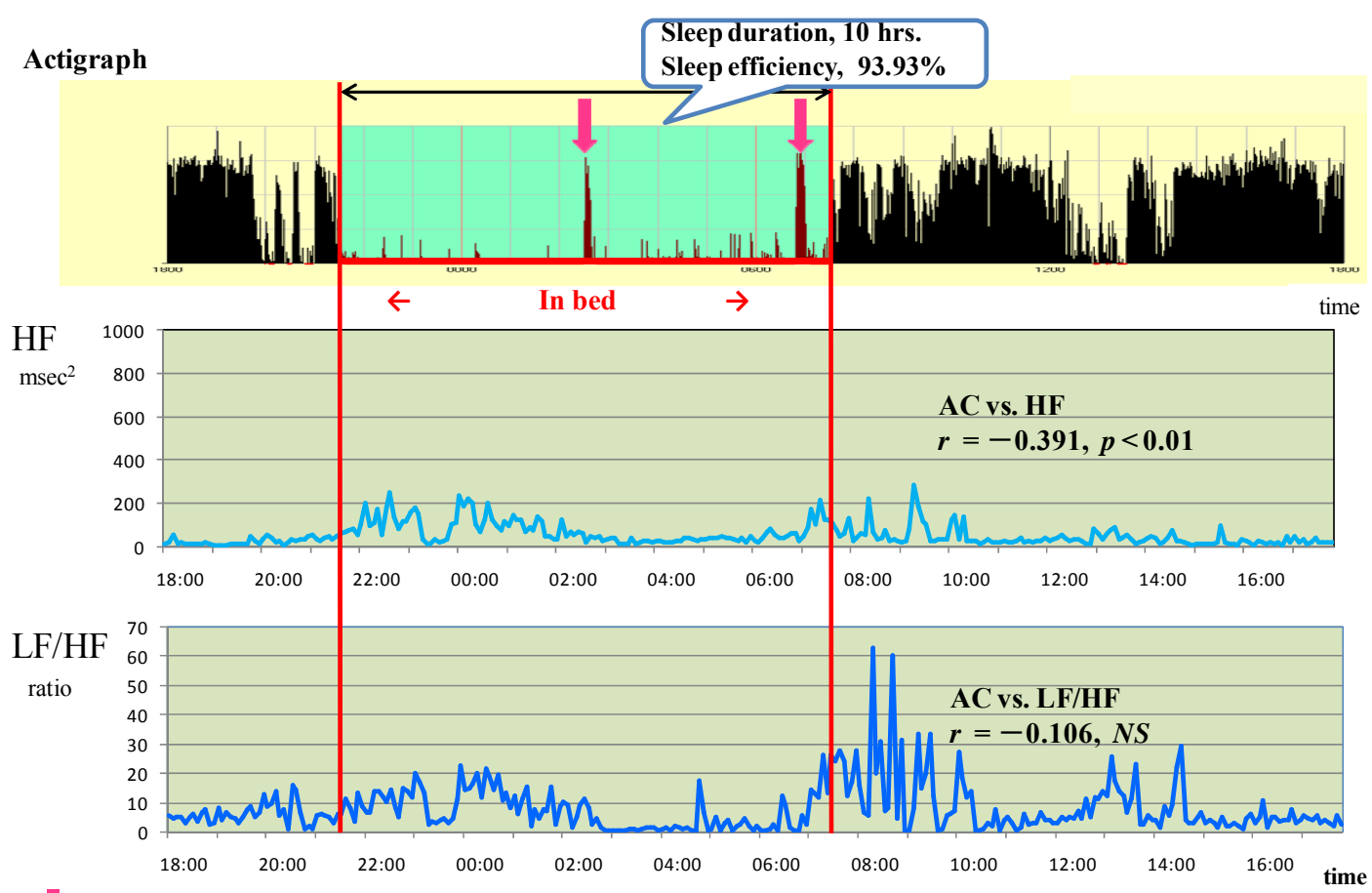

Awoke to use toilet; HF, high frequency; LF/HF, ratio of high-frequency to low-frequency components. Not significant; NS

Figure 3. Typical example of woman aged in her 70s patients with type 2 diabetes who injects insulin four times a day.

\section{DISCUSSION}

Among the healthy women in their 20 s to 40 s, the AC data were significant and negatively correlated with HF but positively correlated with the LF/HF ratio. As for the autonomic nervous system functions, parasympathetic nervous system activity increased significantly and sympathetic nervous system activity decreased significantly at bedtime. It appears that the autonomic nervous system responds well to $\mathrm{AC}$.

The HbA1c level of Case A in her 70s was controlled by the exercise and diet plan she received while visiting the hospital (HbAlc 6.0\%), with a tendency to show the same correlations between the $\mathrm{AC}$ and $\mathrm{HF}$ and between the $\mathrm{AC}$ and $\mathrm{LF} / \mathrm{HF}$ as in healthy women. As for her autonomic nervous system activities, her parasympathetic nervous system activity rose significantly and her sympathetic nervous system activity fell significantly at bedtime. Her sleep efficiency was $96.05 \%$, and sleeping time was approximately 6.5 hours. Her PSQI score was 3 points, so her sleeping condition was good. Because she started treatment at an early stage, and her blood sugar was well controlled (controlled by diet and exercise without oral medicine), the balance of her autonomic nervous system activities was assessed as good.

On the other hand, Cases B, C, and D, whose blood sugar control was not good and who had been on insulin for a long time showed trends that were different from those of healthy subjects.

In Case $\mathrm{B}$, who had been treated with insulin for nearly 30 years, her HbA1c was $6.0 \%$ and she was taking insulin injections three times a day. She had accidentally overdosed on insulin once and developed a low blood sugar level. Her control of her diabetes was poor. Although her parasympathetic nervous system activity rose at bedtime, no significant difference in sympathetic nervous system activities between daytime and bedtime was observed. Her sleep efficiency was $86.84 \%$, and her sleep time was approximately 10 hours.

Case B was being treated with insulin because she was poor at controlling her blood sugar levels, although the HbA1c value was not poor. The balance of her autonomic nervous system activities was poor. Her PSQI score was 15 points, so that it was presumed that both sleep time and sleep quality were a problem.

Case $\mathrm{C}$ had been treated with insulin for 10 years since being diagnosed with diabetes. She was not good at controlling her diabetes, and her dose of insulin was increasing. A weak correlation was seen between $\mathrm{AC}$ and $\mathrm{HF}$, as well as between AC and LF/HF. As for autonomic nervous system activities, parasympathetic nervous system activity rose significantly at bedtime and sympathetic nervous system activity fell significantly. Sleep efficiency was $87.04 \%$, and sleep time was approximately 6 hours. The PSQI score was 9 points, so that her sleep condition 
was poor. Although her sleep hours were not long compared with healthy subjects, her sleep efficiency and sleep quality were presumed to be poor. There appeared to be a difference between her subjective sleep and her objective sleep.

Case D had been treated with insulin for 15 years since being diagnosed with diabetes. Compared with healthy subjects, a weak correlation between AC and HF was seen, but there was no correlation between $\mathrm{AC}$ and $\mathrm{LF} / \mathrm{HF}$. As for autonomic nervous system activity, although HF rose significantly at bedtime, LF/HF did not fall significantly. Sleep efficiency was $93.93 \%$, and her sleep time was approximately 10 hours.

Sympathetic nerve fiber density decreases with advancing age, whereas basic sympathetic nervous system activity increases paradoxically [25]. The LF/HF tends to decline from its peak during the age range of 40 - 50 years, which might reflect a drop in baroreceptor sensitivity [26].

It was determined that Case C's bedtime started early and her sleep hours were long because of advanced age. She woke up late in the morning and was sleeping nearly half a day, so that the amount of activities was small. She frequently awoke to use the toilet at night. There was no problem in that the PSQI score was 6 points, but she had long sleep time. It was considered that she had many arousals during sleep, and there might be a problem in sleep quality.

The sleep times of Cases B and D were long. Although sleep might become shallow and sleep duration might decrease with aging, the number of hours spent resting in bed might increase. Long and short sleep durations are risk factors for cardiac disease, and thus, from the viewpoint of nursing care, patients should sleep well at night by being encouraged to maintain regular hours and increasing activity during the daytime. A decrease in the quality of sleep might exacerbate blood sugar control [27]. Rajendran et al. [28] found a high prevalence of sleep dysfunction in patients with type 2 diabetes. They also found a significant correlation between the duration of diabetes and quality of sleep. Therefore, it is important for healthcare providers to address the quality and duration of sleep in patients with type 2 diabetes.

In comparing sympathetic and parasympathetic nervous system activities during active hours and while asleep, there were no differences, indicating that the responsiveness of the sympathetic and parasympathetic nervous systems to the AC (amount of activity exceeding $0.01 \mathrm{G} / \mathrm{min}$ during an epoch of 1 minute) was low; it was thought that autonomic nervous system function is more unbalanced in patients with type 2 diabetes than in healthy individuals.

HRV was found to decrease in patients with diabetes. However, this occurred before diabetic autonomic neuro- pathy appears clinically [29,30]. Thus, HRV is considered a useful diagnostic index of autonomic neuropathy. The researchers suspected autonomic neuropathy in this patient, and since longer sleep duration is associated with increased risk of metabolic syndrome in older individuals [31], this understanding should provide guidance to suggesting improvements in the patient's lifestyle and health.

\section{LIMITATIONS}

The present study has several limitations because it included healthy women and patients. The study results cannot be generalized due to the small sample size. The present findings need to be validated in a larger cohort of healthy women and patients with type 2 diabetes. Assessments of subjective sleep and the present findings can help support improvements in the quality of life of patients with type 2 diabetes.

\section{CONCLUSIONS}

The AC and HRV were almost precisely correlated, and parasympathetic and sympathetic nervous functions were balanced in healthy women in their 20 s to 40 s.

However, in cases A, C and D, there were no significant differences found between sympathetic nervous function during the daytime hours and while asleep, or between the AC and HRV in women patients with type 2 diabetes. Low correlations between AC and HF and between $\mathrm{AC}$ and LF/HF were observed.

In the typical example of a woman patient in her $70 \mathrm{~s}$ with type 2 diabetes who injects insulin four times a day and an $\mathrm{HbAlc}$ of $10.4 \%$, the PSQI was 6 points. In responses to the PSQI, she answered that the quality of her sleep was not poor. However, the activity of her parasympathetic nervous system was low and that of her sympathetic nervous system was high at night. The quality of sleep of patients who had diabetes for a long period of time was not good even if HbA1c was comparatively well controlled, and their autonomic nervous system activities also tended to be different from those of healthy people. Furthermore, the sleeping times of the patients with type 2 diabetes were longer or shorter than those of healthy women, and in cases where it is particularly longer, it is said the risk of heart disease is increased. From the data derived from this study, it is therefore important to examine autonomic nervous system activities using an objective examination index at an early stage when $\mathrm{HbA1c}$ is within a normal range.

\section{ACKNOWLEDGEMENTS}

The authors would like to express their sincere appreciation for the cooperation extended to the participants and all of the staff at each of 
these institutions.

\section{REFERENCES}

[1] Taub, L.F. and Redeker, N.S. (2008) Sleep disorders, glucose regulation, and type 2 diabetes. Biological Research for Nursing, 9, 231-243. http://dx.doi.org/10.1177/1099800407311016

[2] Grap, M.J., Borchers, C.T., Munro, C.L., Elswick Jr., R.K. and Sessler, C.N. (2005) Actigraphy in the critically ill: Correlation with activity, agitation, and sedation. American Journal of Critical Care, 14, 52-60.

[3] Budhiraja, R., Roth, T., Hudgel, D.W., Budhiraja, P. and Drake, C.L. (2011) Prevalence and polysomnographic correlates of insomnia comorbid with medical disorders. Sleep, 34, 859-867.

[4] Loredo, J.S., Ancoli-Israel, S. and Dimsdale, J.E. (2001) Sleep quality and blood pressure dipping in obstructive sleep apnea. American Journal of Hypertension, 14, 887892. http://dx.doi.org/10.1016/S0895-7061(01)02143-4

[5] Iyer, S.R. (2012) Sleep and type 2 diabetes mellitusclinical implications. Journal of the Association of Physicians of India, 60, 42-47.

[6] Kario, K., Schwartz, J.E., Davidson, K.W. and Pickering, T.G. (2001) Gender differences in associations of diurnal blood pressure variation, awake physical activity, and sleep quality with negative affect: The work site blood pressure study. Hypertension, 38, 997-1002. http://dx.doi.org/10.1161/hy1101.095009

[7] Vgontzas, A.N., Liao, D., Pejovic, S., Calhoun, S., Karataraki, M. and Bixler, E.O. (2009) Insomnia with objective short sleep duration is associated with type 2 diabetes: A population-based study. Diabetes Care, 32, 1980-1985. http://dx.doi.org/10.2337/dc09-0284

[8] Botros, N., Concato, J., Mohsenin, V., Selim, B., Doctor, K. and Yaggi, H.K. (2009) Obstructive sleep apnea as a risk factor for type 2 diabetes. American Journal of Medicine, 122, 1122-1127.

http://dx.doi.org/10.1016/j.amjmed.2009.04.026

[9] Chasens, E.R. and Umlauf, M.G. (2003) Nocturia: A problem that disrupts sleep and predicts obstructive sleep apnea. Geriatric Nursing, 24, 76-81,105. http://dx.doi.org/10.1067/mgn.2003.27

[10] Weiss, J.P., Blaivas, J.G., Stember, D.S. and Brooks, M.M. (1998) Nocturia in adults: Etiology and classification. Neurourology and Urodynamics, 17, 467-472. http://dx.doi.org/10.1002/(SICI)1520-6777(1998)17:5<46 7::AID-NAU2 $>3.0 . \mathrm{CO} ; 2-\mathrm{B}$

[11] Weiss, J.P. and Blaivas, J.G. (2003) Nocturia. Current Urology Reports, 4, 362-366. http://dx.doi.org/10.1007/s11934-003-0007-1

[12] Asplund, R. (2005) Nocturia in relation to sleep, health, and medical treatment in the elderly. BJU International, 96, $15-21$ http://dx.doi.org/10.1111/j.1464-410X.2005.05653.x

[13] Sato, M., Yasuhara, Y., Tanioka, T., Iwasa, Y., Yasui, T., Miyake, M., Kobayashi, H., Kongsuwan, W. and C. Locsin, R. (2013) Changes before and after improvement of subjective sleep state of a man diagnosed with pre-diabetes and sleep disorder. Health, 5, 504-511. http://dx.doi.org/10.4236/health.2013.53A069

[14] Taub, L.F. and Redeker, N.S. (2008) Sleep disorders, glucose regulation, and type 2 diabetes. Biological Research for Nursing, 9, 231-243. http://dx.doi.org/10.1177/1099800407311016

[15] Fiorentini, A., Valente, R., Perciaccante, A. and Tubani, L. (2007) Sleep's quality disorders in patients with hypertension and type 2 diabetes mellitus. International Journal of Cardiology, 114, 50-52. http://dx.doi.org/10.1016/j.ijcard.2006.07.213

[16] Cappuccio, F.P., D’Elia, L., Strazzullo, P. and Miller, M.A. (2010) Quantity and quality of sleep and incidence of type 2 diabetes: A systematic review and meta-analysis. Diabetes Care, 33, 414-420. http://dx.doi.org/10.2337/dc09-1124

[17] Knutson, K.L. (2010) Sleep duration and cardiometabolic risk: A review of the epidemiologic evidence. Best Practice \& Research Clinical Endocrinology \& Metabolism, 24, 731-743. http://dx.doi.org/10.1016/j.beem.2010.07.001

[18] Lamond, N., Tiggemann, M. and Dawson, D. (2000) Factors predicting sleep disruption in Type II diabetes. Sleep, 23, 415-416.

[19] Chasens, E.R., Umlauf, M.G., Pillion, D.J., and Singh, K.P. (2000) Sleep apnea symptoms, nocturia, and diabetes in African-American community dwelling older adults. The Journal of National Black Nurses Association, 11, 25-33.

[20] Burgess, H.J., Trinder, J. and Kim, Y. (1999) Cardiac autonomic nervous system activity during presleep wakefulness and stage 2 NREM sleep. Journal of Sleep Research, 8, 113-122.

http://dx.doi.org/10.1046/j.1365-2869.1999.00149.x

[21] Chung, G.S., Choi, B.H., Jeong, D.U. and Park, K.S. (2007) Noninvasive heart rate variability analysis using loadcell-installed bed during sleep. Proceeding of EMBS of the 29th Annual International Conference of the IEEE, Engineering in Medicine and Biology Society, 22-26.

[22] Shochat, T., Tzischinsky, O., Oksenberg, A. and Peled, R. (2007) Validation of the pittsburgh sleep quality index, Hebrew translation (PSQI-H) in a sleep clinic sample. The Israel Medical Association Journal, 9, 853-856.

[23] Doi, Y., Minowa, M., Uchiyama, M., Okawa, M., Kim, K., Shibui, K. and Kamei, Y. (2000) Psychometric assessment of subjective sleep quality using the Japanese version of the Pittsburgh Sleep Quality Index (PSQI-J) in psychiatric disordered and control subjects. Psychiatry Research, 97, 165-172. http://dx.doi.org/10.1016/S0165-1781(00)00232-8

[24] Buysse, D.J., Reynolds, C.F. 3rd, Monk, T.H., Berman, S.R. and Kupfer, D.J. (1989) The Pittsburgh sleep quality index-A new instrument for psychiatric practice and research. Psychiatry Research, 28, 198-213. http://dx.doi.org/10.1016/0165-1781(89)90047-4

[25] Brandenberger, G., Viola, A.U., Ehrhart, J., Charloux, A., Geny, B., Piquard, F. and Simon, C. (2003) Age-related changes in cardiac autonomic control during sleep. Jour- 
nal of Sleep Research, 12, 173-180. http://dx.doi.org/10.1046/j.1365-2869.2003.00353.x

[26] Ohtuka, K. (2003) 3rd International symposium workshop on circadian rhythms and clinical chronotherapy. Biomedicine \& Pharmacotherapy, 57, 11-16.

[27] Knutson, K.L., Ryden, A.M., Mander, B.A. and Van Cauter, E. (2006) Role of sleep duration and quality in the risk and severity of type 2 diabetes mellitus. Archives of Internal Medicine, 166, 1768-1774. http://dx.doi.org/10.1001/archinte.166.16.1768

[28] Rajendran, A., Parthsarathy, S., Tamilselvan, B., Seshadri, K.G. and Shuaib, M. (2012) Prevalence and correlates of disordered sleep in Southeast Asian Indians with type 2 diabetes. Diabetes \& Metabolism Journal, 36, 70-76. http://dx.doi.org/10.4093/dmj.2012.36.1.70

[29] Ayas, N.T., White, D.P., Manson, J.E., Stampfer, M.J.,
Speizer, F.E., Malhotra, A. and Hu, F.B. (2003) A prospective study of sleep duration and coronary heart disease in women. Internal Medicine, 163, 205-209. http://dx.doi.org/10.1001/archinte.163.2.205

[30] Ewing, D.J., Campbell, I.W., Murray, A., Neilson, J.M. and Clarke, B.F. (1978) Immediate heart-rate response to standing simple test for autonomic neuropathy in diabetes. British Medical Journal, 1, 145-147. http://dx.doi.org/10.1136/bmj.1.6106.145

[31] Bellavere, F., Balzani, I., De Masi, G., Carraro, M., Carenza, P., Cobelli, C. and Thomaseth, K. (1992) Power spectral analysis of heart-rate variations improves assessment of diabetic cardiac autonomic neuropathy. Diabetes, $\mathbf{4 1}, 812-817$.

http://dx.doi.org/10.2337/diab.41.5.633 